\title{
A formação inicial de professores e a inserção em contextos escolares: um estudo bibliométrico
}

\author{
Luciana Cristina Cardoso* \\ Daniel Mill** \\ Maria Iolanda Monteiro***
}

\begin{abstract}
Resumo
Sob a perspectiva de que a profissão docente é construída ao longo da vida e de que a formação inicial se mostra como momento singular neste processo, o estudo procura revelar a representatividade da temática formação inicial de professores vinculada às experiências de ensino-em-contexto em pesquisas brasileiras. Para isso, foram tomadas como objeto de estudo bibliométrico as 3.468 teses, defendidas em programas de Pós-Graduação em Educação, catalogadas numa base do Grupo Horizonte (Grupo de Estudos e Pesquisas sobre Inovação em Educação, Tecnologias e Linguagens - UFSCar). A pesquisa bibliométrica revela que a formação inicial, mediada por vivências em contextos escolares, está presente em 11 teses de um total de 3.468 pesquisas. As análises indicam que, apesar de haver estudos relevantes para a área, a formação em contexto, marcada por experiências que vão além das Práticas de Ensino e dos Estágios Supervisionados, não está inserida no cenário acadêmico de modo representativo. Dentre algumas contribuições importantes para a linha de formação docente, o estudo indicou também que as pesquisas versam sobre programas formativos institucionais e que em nenhuma delas foi possível identificar a criação de um espaço formativo, caracterizado também enquanto intervenção da pesquisa, o que sugere uma possível carência de construção, implementação e análise de novos programas, como de espaços formativos concebidos sob a perspectiva híbrida ou virtual.
\end{abstract}

Palavras-chave: Formação de professores. Aprendizagem profissional. Prática docente.

* Doutora em Educação pela Universidade Federal de São Carlos (UFSCar).

** Doutor em Educação pela Universidade Federal de São Carlos (UFSCar). Professor do Departamento de Educação da Universidade Federal de São Carlos (UFSCar).

*** Doutora em Educação pela Universidade Federal de São Carlos (UFSCar). Professora do Departamento de Teorias e Práticas Pedagógicas da Universidade Federal de São Carlos (UFSCar). 


\section{Introdução}

Este texto discute a formação inicial de professores considerando os momentos de inserção do estudante no contexto de trabalho futuro, caracterizados por estágios supervisionados e práticas de ensino, durante a formação. Compreendidos como experiências formativas em contexto, tais momentos se mostram propícios para a apropriação de elementos constitutivos da aprendizagem da docência, como: o estabelecimento de relações entre teoria e prática; aprendizagem pela experiência e conhecimento/exploração de metodologias, conteúdos e intervenções de modo estruturado e orientado por docentes da universidade e em parceria com professores experientes da educação básica. Ponderamos que essa formação em contexto, parte de um importante processo, merece atenção de investigadores da área educacional.

Nesse sentido, o objetivo central deste estudo foi o de mapear pesquisas de doutorado realizadas nos primeiros anos deste século XXI, em Programas de Pós-Graduação em Educação brasileiros. Ou seja, buscamos analisar produções científicas que investiram em projetos ou programas de interação universidade-escola na perspectiva de aproximação do futuro professor (licenciando em Pedagogia) ao contexto do trabalho docente. Parte-se do princípio de que o interesse de teses nesses projetos ou programas pode indicar a avaliação/construção de estratégias e/ou projetos pilotos que visam à melhoria da formação inicial de professores, realizada pelas instituições. Desse modo, realizou-se um estudo bibliométrico com foco em pesquisas sobre a aprendizagem da docência na formação inicial de professores.

Assim, organizamos o texto em algumas seções, destinadas a: delimitar a temática, apresentar uma breve revisão de literatura sobre o assunto, indicar a proposta metodológica bibliométrica e o material a ser analisado, sistematizar e analisar os dados. Por fim, apresentamos ainda algumas considerações sobre a discussão feita, seguidas das referências bibliográficas utilizadas.

\section{Delimitação da temática: sobre aprendizagem da docência, formação inicial e estágios}

A formação inicial de docentes é tema recorrente em muitos estudos que contemplam a aprendizagem da profissão e os desafios aos quais professores iniciantes se deparam no início de suas carreiras. Alguns autores (CAVACO, 1995; MARIANO, 2006; GATTI; BARRETO; ANDRE, 2011; MARIANO; LIMA, 2012; MARCELO; VAILLANT, 2012; GATTI, 2012) indicam que a área de 
formação docente deve considerar, entre outros tantos aspectos, demandas elencadas por professores iniciantes quando questionados sobre as principais dificuldades enfrentadas no início da profissão. Dentre elas, destacam-se:

- Ajustes ao trabalho pedagógico em sala de aula;

- Período de buscas de apoio e de informações;

- Estabelecimento de relações interpessoais no contexto de trabalho; e

- Ajustes às normas da rede de ensino em que atua.

O início da carreira do professor é aqui compreendido como um dos momentos formativos pelos quais os professores se constituem docentes. Considerando as características decorrentes dessa fase profissional, as pesquisas sobre a formação inicial debruçam-se, em geral, sobre a análise de currículos de cursos de licenciatura, de compreensão sobre como se aprende a ensinar e sobre experiências de inserção em campo - por meio de estágios supervisionados, práticas de ensino, projetos de extensão universitária ou, ainda, programas que se configuram como políticas públicas, como é o caso do Programa Institucional de Bolsas de Iniciação à Docência (Pibid) e do Pro-Licenciatura.

Em levantamento feito há alguns anos, Andre (2007) aponta uma mudança no foco das pesquisas sobre formação de professores. A autora indica que, em 1992, 47\% das pesquisas versavam sobre a formação inicial de professores, ao passo de que, em 2002, esse índice era de apenas $24 \%$. Segundo ela, a mudança se deu, em grande parte, devido ao avanço de linhas de pesquisa sobre o pensamento do professor, sua identidade e profissionalização.

Estudos sobre a formação de professores em países como Chile (ROMERO, 2011), Espanha (GARCIA, 1999) e Estados Unidos (COCHRAN-SMITH, 2014), por exemplo, indicam como necessária uma revisão do currículo dos cursos de formação inicial de professores e, sobretudo, das relações que se estabelecem entre a universidade e as escolas. São enfatizadas fortemente as iniciativas de formação em contexto (SCHOENFELD, 1998), as quais tomam professores experientes como mentores de professores iniciantes. Tais iniciativas são comumente denominadas, em tais países, como período de iniciação profissional ou programas de indução da docência. No Brasil, têm-se acompanhado algumas experiências neste sentido, como as relatadas por Andre (2012). Neste estudo, a autora identificou não apenas iniciativas de apoio ao professor iniciante, mas o delineamento de políticas públicas para um efetivo acompanhamento das práticas por eles realizadas.

Anterior às experiências mencionadas por Andre (2012), podemos citar também o Programa de Mentoria $^{1}$, realizado por docentes e pesquisadores do departamento de Teorias e Práticas Pedagógicas (DTPP) e do Programa de Pós-graduação em Educação da UFSCar, vinculados ao Portal dos 
Professores da mesma universidade. Este programa teve como mote o acompanhamento, por meio da internet, de professoras iniciantes de escolas públicas de vários municípios do país. As professoras iniciantes contavam com o apoio de professoras já experientes (Mentoras) e, por meio de interações virtuais, relatavam suas angústias, suas dificuldades e dilemas. Este programa não se configurou enquanto uma política pública, mas foi amplamente reconhecido por seu apoio ao início da docência e sua inovação, por se tratar de um acompanhamento online (REALI; TANCREDI, 2010).

Apesar de investimentos significativos para a área, nota-se que tais iniciativas são, ainda, recentes e pontuais. Envolvem programas de acompanhamento ao professor iniciante (e não ao futuro professor), o que evidencia a necessidade de pesquisas que tomem como objeto de análise a formação inicial de professores, seus currículos e programas de inserção em contextos escolares, como as Práticas de Ensino ou os Estágios Supervisionados.

Por outro lado, em publicações recentes (MORETTI, 2011; PANIZZOLO et al., 2012; DALFORNO; CARDOSO; RINALDI, 2013) são encontrados modelos bastante inovadores para situações de aprendizagem em contexto no âmbito dos estágios supervisionados. Os dois primeiros trabalhos tratam do Modelo de Residência Pedagógica, desenvolvido no curso de Pedagogia da Universidade Federal de São Paulo (Unifesp) - Guarulhos/SP, e o último do modelo de Estágio Supervisionado de Ensino do curso de Pedagogia da UFSCar na modalidade a distância. Os dois modelos de estágio consideram a aprendizagem da docência e o desenvolvimento profissional de professores como norteadores para as intervenções pedagógicas realizadas nas esferas contempladas: escola da educação básica e universidade.

O modelo de Estágio Supervisionado de Ensino da UFSCar, no entanto, se difere em relação à modalidade de ensino e à inserção de aprendizagens vinculadas ao uso de tecnologias digitais de informação e comunicação quanto ao escopo do trabalho desenvolvido com professores parceiros, já que se trata de um curso a distância.

Referenciados nas iniciativas apresentadas anteriormente e pautados na compreensão de que a docência é processual, aprendida ao longo da vida (MIZUKAMI, 2004) e de que a formação inicial se constitui um período singular neste processo formativo, (GARCIA, 1999), questionamo-nos, neste texto, sobre a atenção dada à temática pelas produções científicas do campo educacional na última década. Por meio de um estudo bibliométrico, averiguamos a existência de pesquisas desenvolvidas sobre a formação inicial de professores em contexto numa perspectiva que considera a aprendizagem da docência de modo situado, contextualizado, intencional e reflexivo. Buscamos analisar quantas e 
quais teses versam sobre a aproximação entre universidade-escola, tendo como foco a formação do futuro professor e a aprendizagem da docência. Se existem, como se caracterizam tais pesquisas? Antes de analisar a base de dados, procedendo ao estudo bibliométrico, situaremos a importância da temática formação inicial docente em contexto, segundo a literatura da área. Em seguida, apresentaremos os caminhos metodológicos percorridos na análise bibliométrica.

\section{Formação Inicial de Professores nos cursos de Licenciatura em Pedagogia: aprendizagem da docência e formação a partir de experiências em contexto}

O curso de Licenciatura em Pedagogia surge em 1939, mas se consolida como curso de formação de professores para a atuação nos níveis infantil e fundamental somente após a aprovação da atual Lei de Diretrizes e Bases da Educação Nacional, Lei n. 9394, de 20 de dezembro de 1996 (BRASIL, 1996). Até então, a formação inicial de professores ocorria primeiramente no nível médio, mas após a aprovação das "Diretrizes Nacionais para a Licenciatura em Pedagogia", em 2005 (BRASIL, 2005), a formação inicial restringe-se à graduação em Pedagogia.

Os efeitos decorrentes de tal mudança trazem uma complexidade ainda maior ao fazer docente e à necessidade de uma formação mais sólida. Refletem diretamente na qualidade dos processos de ensino e aprendizagem vivenciados em sala de aula, sobretudo quando se trata de professores iniciantes, com pouco contato com a realidade do trabalho docente. Assim, para Penin (2011), urge uma formação em caráter interdisciplinar, na qual as práticas de ensino e os estágios supervisionados sejam o eixo norteador sob o qual teorias e disciplinas se debrucem.

Nesse sentido, como já destacamos anteriormente, a necessidade de experiências de formação inicial em contexto se justifica, ainda, em decorrência das dificuldades já conhecidas pela literatura, referentes ao início da docência: ajustes ao trabalho pedagógico em sala de aula, busca de apoios e informações, estabelecimento de relações interpessoais na escola, ajustes às normas da rede de ensino em que atua etc. (CAVACO, 1995; GARCIA, 2002; MARIANO, 2006).

A necessidade de se conhecer bem a matéria que se ensina é apontada por Shulman (1987), Mizukami e Reali (2010) e outros como fundamental e primeiro passo para que conteúdos sejam de fato aprendidos. No entanto, além de conhecer e dominar o conteúdo específico, o professor deve conhecer e dominar estratégias metodológicas para bem ensiná-lo. Assim, considera-se que ele precisa adquirir o conhecimento pedagógico e conhecimento pedagógico do conteúdo (MIZUKAMI et al., 2002; SHULMAN, 2005). Os conhecimentos delineados acima compõem o que Shulman (2005) 
denominou "Base de conhecimento para a docência". Como já mencionamos, alguns esforços são feitos por parte das instituições formadoras, para o estabelecimento de relações férteis entre escolauniversidade e de situações de aprendizagem da docência em contexto. Todavia, há limitações.

Para Feiman, Buchmann (1988) e Zeichner (1990), perpetua-se a concepção das práticas de inserção profissional como atividades não estruturadas e muito menos organizadas, mantendo-se a ideia de que para uma formação de qualidade basta que os futuros professores sejam colocados em classes com "bons" professores.

Flores (2010) destaca que, por ser uma profissão com a qual se tem contato durante toda uma trajetória de estudante, a docência não é exatamente nova aos futuros profissionais. Foi sendo constituída ao longo de uma vida e é fortemente marcada por crenças, modelos e imagens sobre os processos de ensino e aprendizagem, adquiridos por anos e anos de aprendizagem pela observação (LORTIE, 1975). Atividades práticas em contextos escolares se mostram como adequados momentos formativos para o rompimento de tais elementos, já que potencializam a tomada de consciência de situações que vão além dos aspectos abordados pela universidade.

Nesta direção, Schoenfeld (1998) propõe uma teoria de "ensino-em-contexto". Para ele, a todo instante, o professor faz escolhas e age em função de um contexto institucional e, desse modo, a docência trata de processos de ensino e aprendizagem situados, contextualizados, e não generalizados, como são frequentemente explorados em cursos de formação. O modelo proposto por Schoenfeld (1998) tem como foco a sala de aula e como ela é vista pelo professor, contribuindo para a compreensão de escolhas particulares, mitos, crenças e compreensões trazidas pelos docentes sobre processos de ensino e aprendizagem.

Diante das necessidades formativas mencionadas anteriormente e de atividades em contexto que potencializem a compreensão da prática docente como profissão, observam-se reestruturações em vários cursos de formação inicial de professores. Em função dessas reestruturações, imaginamos que pesquisas envolvendo a aproximação escola-universidade com foco na formação do futuro professor sejam reveladoras (ou não) de tais movimentos. Nesse sentido, entendemos que esta pesquisa bibliométrica, com foco em teses de doutorado em Educação, traz importantes contribuições. Nas próximas seções, apresentamos o tratamento metodológico dos dados da pesquisa, seguido da análise dos dados e de algumas considerações decorrentes do estudo. 


\section{Caminhos da Pesquisa: a análise bibliométrica como estratégia metodológica}

Desde a sua criação, em 2007, o Grupo Horizonte (Grupo de Estudos e Pesquisas sobre Inovação em Educação, Tecnologias e Linguagens - UFSCar) vem envidando esforços para compreender, sob diferentes perspectivas, os processos pedagógicos mediados pelas tecnologias digitais - com particular atenção à formação de professores. Com a preocupação de identificar e acompanhar tipos e tendências de conhecimentos produzidos e disseminados nessa área, pesquisadores do Grupo Horizonte têm adotado as estratégias metodológicas típicas da bibliometria (MATTOS, 2004; SANTOS; KOBASHI, 2009; ARAUJO; ALVARENGA, 2011), caracterizada por análises qualiquantitativas em bases de dados constituídas por produções científicas da área, tais como teses, livros, periódicos, anais de eventos etc. Entende-se que os estudos bibliométricos são muito adequados para mapear tipos e tendências dos estudos de uma área, além de identificar os temas mais recorrentes ou silenciados em pesquisas e publicações da área.

Nesse sentido, o presente trabalho analisou, pela bibliometria, a temática aprendizagem da docência em atividades de estágio e em práticas de ensino durante a formação inicial, tendo como foco o curso de Licenciatura em Pedagogia, que é responsável pela formação inicial do professor da Educação Infantil, dos anos iniciais do Ensino Fundamental e ainda, do Ensino Médio na modalidade Normal e de cursos de Educação Profissional. Para esta análise bibliométrica, utilizamos uma base de dados do Grupo Horizonte, constituída por teses de doutorado ${ }^{2}$, e que pode ser assim caracterizada:

- são 3.468 teses catalogadas em banco de dados Access $^{3}$, considerando seus metadados: título, autor, ano e instituição de defesa, resumo e termos-chave;

- há teses de 26 programas de doutorado em Educação, todos classificados pela Capes ${ }^{4}$ com nota igual ou superior a 4 ;

- foram defendidas entre 2002 e 2012, constituindo um recorte histórico de aproximadamente 10 $\operatorname{anos}^{5}$ de defesas (observamos que aproximadamente $80 \%$ das teses catalogadas foram defendidas após o ano de 2006); e

- possuem, no conjunto, 5.847 termos diferentes (sem repetições), com um total de 15.318 recorrências em todas as teses.

Em atenção aos cuidados apresentados por Mattos (2004), registra-se que adotamos o rigor metodológico exigido pelos estudos bibliométricos, tanto na estruturação da base de dados (que exige 
cuidado e coerência na recolha e catalogação das informações no banco de dados) quanto na análise das informações catalogadas. As análises bibliométricas podem ser realizadas em bases que permitam analogias, comparação, levantamentos estatísticos e filtros das informações. Para isso, a catalogação da Base de Teses do Grupo Horizonte foi cuidadosamente organizada, possibilitando a manipulação e sistematização das seguintes informações das teses: título da tese, autoria, palavras-chave, resumo do trabalho, ano e instituição da defesa. Assim, pela aplicação de filtros e análises dessas informações, buscamos respostas à seguinte questão norteadora: como a temática formação de professores em contexto baseada em programas de interação universidade-escola tem sido tratada em pesquisas/teses da área educacional?

Recorrendo às estratégias da bibliometria, filtramos as teses de interesse por meio da classificação, organização, categorização, quantificação e análise de cada disposição dos dados. A ideia foi buscar padrões e tendências nas produções catalogadas com foco na temática eleita para este artigo.

\section{Sistematização e análises qualiquantitativas dos dados}

Por meio dos termos-chave e/ou dos títulos dos trabalhos, foi feito um mapeamento, identificando as produções da Base de Teses que trataram da temática "formação de professores em contexto". De partida, a tarefa configurou-se como um desafio, porque identificamos muitos termos relacionados à formação de professores. Essa profusão terminológica exigiu cuidados no tratamento bibliométrico.

Primeiramente, buscamos mapear as teses relacionadas à formação de professores em geral. Nessa etapa, percebeu-se uma dificuldade técnica: o volume de teses sobre professores é elevado. Foram identificadas 661 teses com foco na formação de professores, mesmo sem considerar-se termos indiretos (como prática pedagógica, profissionalização do magistério etc.). Isto representa pouco mais de $19 \%$ das teses da base.

A partir dessas 661 teses, filtramos aquelas que tratavam especificamente sobre a aprendizagem da docência em atividades de estágio e/ou em práticas de ensino durante a formação inicial. Para identificar as teses com foco na formação docente em contexto durante a formação inicial, adotamos as seguintes subcategorias temáticas:

- aprendizagem da docência/aprendizagem docente;

- formação inicial/Pedagogia;

- estágio (supervisionado/curricular); e 
- professor pesquisador e relação universidade-escola (extensão universitária).

Assim, observa-se que o presente estudo centrou seus esforços em pesquisas que abordavam a interação escola-universidade em disciplinas de estágio supervisionado e práticas de ensino, ou em situações de inserção em contexto propostas por programas de extensão universitária. Este foco de pesquisa se deve, essencialmente, em razão de limitações também já sinalizadas pela literatura da área em relação às experiências de inserção em contextos escolares. Dentre essas limitações, destacam-se as apontadas por Zeichner (1990) e Garcia(1999), como a compreensão das atividades práticas como aprendizagens não organizadas e estruturadas, que tomam como pressuposto que para aprender a ser professor é necessário apenas que os licenciandos sejam inseridos em contexto escolar sob a orientação de "bons professores"; ausência ou fragilidades nas relações entre os referenciais teóricos estudados nos cursos e os programas das atividades práticas, quando há programas; a falta de preparação dos "bons professores" na orientação e supervisão dos licenciandos que são por eles acompanhados - ser um "bom professor" não significa, necessariamente, ser um bom formador -; e o baixo prestígio de disciplinas/projetos dessa natureza no interior dos próprios cursos de formação.

Considerando limites e possibilidades de momentos de inserção profissional em contextos escolares durante a formação inicial e o modo como essa temática é enfaticamente tratada pela literatura (sobretudo internacional: GARCIA, 1999; VAILLANT; MARCELO, 2012; COCHRANSMITH, 2014), o número de teses que identificamos com interesse nesta área pareceu-nos animador. Após análise dos títulos e termos-chave das 661 teses, identificamos 83 produções sobre o assunto foco deste texto. Ou seja, havia 2,39\% do total de teses (12,56\% das teses sobre formação de professores), relacionadas à aprendizagem da docência em atividades de estágio e em práticas de ensino durante a formação inicial (Tabela I).

Tabela 1 - Relação e quantificação dos termos pertinentes à aprendizagem da docência pelos estágios e em práticas de ensino durante a formação inicial

\begin{tabular}{|l|c|c|}
\hline \multicolumn{1}{|c|}{ Subtemáticas } & \multicolumn{2}{c|}{ Quant. Teses } \\
\cline { 2 - 3 } & Termos-chave & Títulos \\
\hline - Aprendizagem da docência / Aprendizagem docente & 8 & 8 \\
\hline - Formação inicial / Pedagogia & 24 & 34 \\
\hline - Estágio (supervisionado/curricular) & 24 & 14 \\
\hline - Professor pesquisador & 3 & 4 \\
\hline - Relação universidade-escola / extensão & 2 & 2 \\
\hline \multicolumn{1}{|r|}{ Total absoluto (valor bruto): } \\
\hline Total relativo (valor líquido por categoria): & $\mathbf{6 1}$ & $\mathbf{6 2}$ \\
\hline Total efetivo (valor líquido final) & $\mathbf{5 5}$ \\
\hline
\end{tabular}

Fonte: Elaborado pelos autores. 
Concentramos a análise nas 83 teses e identificamos, logo de início, que em 25 delas alguma subtemática (relação da Tabela II) aparece tanto nos títulos quanto nas palavras-chave. Em teoria, essas teses mereceriam atenção especial, pois o próprio autor da tese considerou o assunto importante o suficiente para aparecer nos termos-chave e também no título do trabalho. No restante das teses, as subtemáticas aparecem apenas no título ou como alguma das palavras-chave.

Em seguida, fizemos uma leitura atenta e minuciosa dos títulos e do conjunto de termos-chave de cada uma das 83 teses filtradas, buscando identificar mais apuradamente os trabalhos que estudaram a temática central, foco deste artigo. Ao final, selecionamos 18 teses para tratamento detalhado, por serem as produções mais próximas do interesse do nosso estudo. Todavia, após leitura dos resumos dessas pesquisas, identificamos que apenas 11 trabalhos estudaram, especificamente, a aprendizagem da docência pelos estágios e em práticas de inserção em contexto escolar durante a formação inicial, em cursos de Licenciatura em Pedagogia.

Os outros sete estudos tratavam de assuntos alheios ao nosso objetivo: observamos que duas pesquisas versaram sobre estágio ou prática de ensino em outras licenciaturas (educação física e matemática), enquanto uma outra tese teve como foco o professor de física do Ensino Médio. Desta forma, não trataram especificamente da docência nos anos iniciais do Ensino Fundamental, que é o nosso objeto de análise. Uma tese discorria sobre reformas políticas na década de 90, e outras duas tomavam experiências de estágio como instrumento de análise do desenvolvimento profissional de professores experientes. A última tese excluída do nosso estudo abordava a questão do cuidado na formação do professor. Enfim, nossa análise centrou-se em 11 produções científicas.

De início, fizemos o agrupamento e quantificação dos termos-chave atribuídos pelos autores das 11 teses selecionadas e elaboramos um diagrama com o resultado do agrupamento (Figura 1). Observase que o tamanho da palavra no diagrama equivale à quantidade de vezes que o assunto figurou entre os termos-chave. Assim, percebe-se que o termo estágio supervisionado é o mais utilizado pelos autores das 11 teses. 
Figura 1 - Disposição gráfica dos termos-chave das 11 teses selecionadas

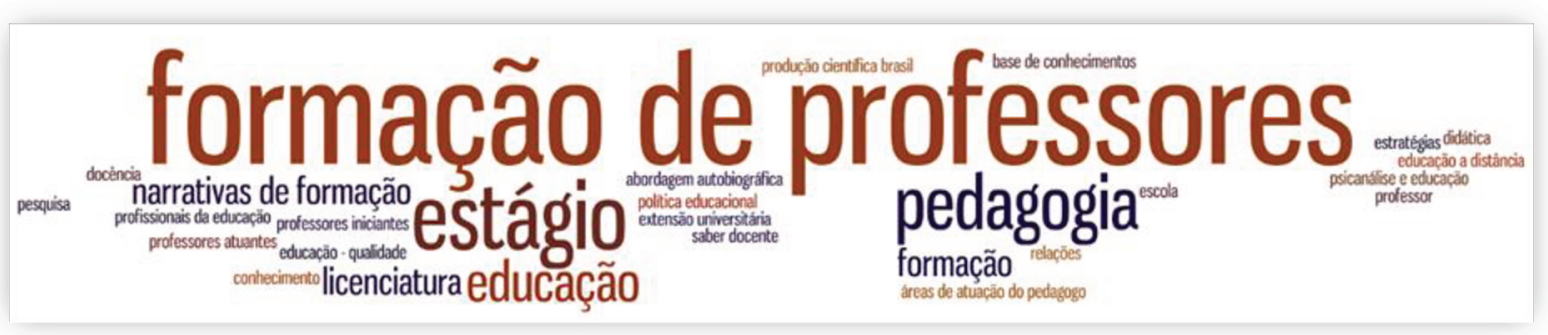

Fonte: Elaborado pelos autores.

Pela disposição gráfica dos termos-chave utilizados pelas teses selecionadas, apresentada na Figura 1, observamos que os assuntos mais tratados nas 11 teses selecionadas foram, nesta ordem: estágio supervisionado ( 6 teses), formação profissional de professores (3 teses), formação inicial de professores ( 3 teses), formação ( 3 teses), formação de professores ( 2 teses), educação ( 2 teses) e professor ( 2 teses). Cada um dos outros termos apareceu em apenas uma tese.

Finalmente, no universo de 3.468 teses, restou para análise um conjunto de 11 teses $(0,3 \%$ das produções da base), com as quais trabalharemos com mais detalhes a partir da próxima seção.

\section{Análise das teses selecionadas}

Em razão das consideraç̃̃es anteriores, nos surpreendeu a identificação feita por Andre (2007) de uma redução no número de pesquisas relacionadas à formação inicial nos últimos anos. A nossa hipótese era que boa parte dos estudos analisados se debruçasse sobre essa fase da carreira e/ou suas derivações (experiências de inserção profissional docente, estágios supervisionados e/ou práticas de ensino, relações de parceria entre escolas-universidades mediadas por processos reflexivos de aprendizagem da docência).

Nosso estudo pode servir de indicativo para confirmar as revelações feitas por Andre (2007), na medida em que somente 11 produções (entre 3.468 teses em educação) estabeleceram as relações por nós delineadas entre: formação inicial de professores, inserção profissional orientada/supervisionada em contexto durante a graduação e parcerias entre escola-universidade. A Tabela 3 apresenta a relação dessas teses, incluindo título, autor, ano de defesa e Instituição de Ensino Superior em que foram defendidas. 
Tabela 3 - Relação de teses com foco específico na aprendizagem da docência pelos estágios e práticas de ensino durante a formação inicial (continua)

\begin{tabular}{|c|c|c|c|c|}
\hline & TÍTULO DA TESE & AUTOR & ANO & IES \\
\hline \multirow{4}{*}{ 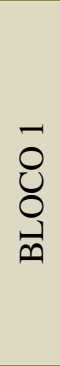 } & $\begin{array}{l}\text { Ensinando a ensinar ou vivendo para aprender? A interação } \\
\text { entre os conhecimentos de um professor atuante e de um } \\
\text { aspirante, como subsídio para aprendizagem da docência }\end{array}$ & $\begin{array}{l}\text { Marcos D. } \\
\text { Longhini }\end{array}$ & 2006 & UFSCar \\
\hline & O estágio curricular e a formação de qualidade do pedagogo & $\begin{array}{l}\text { Marilene G. } \\
\text { Corte }\end{array}$ & 2010 & PUC-RS \\
\hline & $\begin{array}{l}\text { Prática de ensino e formação de professores: um estudo de caso } \\
\text { sobre a relação universidade-escola em cursos de licenciatura }\end{array}$ & $\begin{array}{l}\text { Hamilton G. } \\
\text { Wielewicki }\end{array}$ & 2010 & UFRGS \\
\hline & $\begin{array}{l}\text { Tecendo uma manhã: o estágio supervisionado no curso de } \\
\text { Pedagogia mediado pela extensão universitária }\end{array}$ & $\begin{array}{l}\text { Marise M. } \\
\text { Rosa }\end{array}$ & 2010 & $\begin{array}{l}\text { UNESP } \\
\text { Marília }\end{array}$ \\
\hline \multirow{3}{*}{ 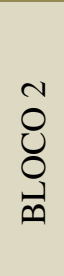 } & $\begin{array}{l}\text { O conhecimento de si: narrativas do itinerário escolar e } \\
\text { formação de professores }\end{array}$ & $\begin{array}{l}\text { Elizeu C. } \\
\text { Souza }\end{array}$ & 2004 & UFBA \\
\hline & $\begin{array}{l}\text { Formação inicial de professores: problematizações, } \\
\text { reatualizações de discursos e produção de narrativas }\end{array}$ & $\begin{array}{l}\text { Kelly C. } \\
\text { Silva }\end{array}$ & 2011 & UNICAMP \\
\hline & $\begin{array}{l}\text { Formação do pedagogo: um olhar sobre a trajetória profissional } \\
\text { dos/as egressos/as do curso de licenciatura em Pedagogia da } \\
\text { UPE-Campus Garanhuns de } 1996 \text { a } 2010\end{array}$ & $\begin{array}{l}\text { Adelina M. } \\
\text { Bizarro }\end{array}$ & 2012 & UERJ \\
\hline
\end{tabular}

Tabela 3 - Relação de teses com foco específico na aprendizagem da docência pelos estágios e práticas de ensino durante a formação inicial (conclusão)

\begin{tabular}{|c|c|c|c|c|}
\hline \multicolumn{2}{|r|}{ TÍTULO DA TESE } & AUTOR & ANO & IES \\
\hline$\overbrace{0}^{\infty}$ & $\begin{array}{l}\text { A formação do professor pesquisador na produção científica } \\
\text { dos encontros nacionais de didática e prática de ensino: 1994- } \\
2000\end{array}$ & $\begin{array}{l}\text { Silvana } \\
\text { Ventorim }\end{array}$ & 2005 & UFMG \\
\hline$\stackrel{0}{0}$ & $\begin{array}{l}\text { A pesquisa na formação de professores: a perspectiva do } \\
\text { professor pesquisador }\end{array}$ & $\begin{array}{l}\text { Noeli T. } \\
\text { Signorini }\end{array}$ & 2006 & Unicamp \\
\hline $\begin{array}{l}+ \\
0 \\
0 \\
0 \\
\end{array}$ & $\begin{array}{l}\text { A formação inicial de professores on-line: possibilidades, } \\
\text { contradições e desafios: } 2000-2005\end{array}$ & $\begin{array}{l}\text { Fábia M. } \\
\text { Vieria }\end{array}$ & 2009 & UnB \\
\hline $\begin{array}{l}n \\
0 \\
0 \\
0 \\
\\
\end{array}$ & $\begin{array}{l}\text { Qualidade da formação inicial de pedagogos: indicadores na } \\
\text { visão de egressos }\end{array}$ & $\begin{array}{l}\text { Josimar A. } \\
\text { Vieira }\end{array}$ & 2010 & PUC-RS \\
\hline
\end{tabular}

Fonte: Elaborado pelos autores.

Com base na Tabela 3, em relação ao ano de publicação das teses, observamos uma incidência maior de defesas em 2010, com quatro produções e, em seguida, temos duas teses defendidas em 2006. As outras se distribuem entre 2004 e 2012. Em relação à instituição em que a tese foi defendida, observa-se que há duas produções da Unicamp e duas da PUC-RS. As outras pesquisas foram desenvolvidas na UERJ, UFBA, UFMG, UFRGS, UFSCar, UnB e UNESP-Marília ${ }^{7}$.

Para proceder à análise, agrupamos as teses por aproximação das temáticas. Essa categorização foi feita pela leitura atenta dos resumos e pela identificação de elementos específicos da proposta no corpo da tese: objetivo, proposta metodológica, resultados etc. Enfim, estabelecemos cinco blocos de assuntos priorizados pelas investigações de doutorado selecionadas, quais sejam: 
- Bloco 1: contribuições de atividades de inserção em contexto escolar e de parcerias escolauniversidade para a formação inicial do professor - bloco com quatro teses;

- Bloco 2: formação inicial de professores a partir da perspectiva da trajetória profissional e do uso de narrativas escritas - bloco com três teses;

- Bloco 3: formação do professor na perspectiva do professor-pesquisador - bloco com duas teses;

- Bloco 4: formação inicial de professores online - bloco com apenas uma tese;

- Bloco 5: qualidade da formação em curso de licenciatura em Pedagogia na perspectiva de egressos - bloco com apenas 1 uma tese.

As teses agrupadas no Bloco 1 têm como eixo comum contribuições de atividades de inserção em contexto escolar e de parcerias escola-universidade para a formação de professores. Longhini (2006) investigou a base de conhecimentos para a docência a partir do referencial teórico de Lee Shulman e das narrativas produzidas por duas licenciandas em Pedagogia. Uma delas professora já experiente, e a outra uma aspirante à professora. Os resultados mostraram que as dificuldades enfrentadas no início da carreira são muito similares e que ambas vivenciaram semelhantes tensões e angústias; que a experiência garante a consolidação de esquemas e/ou estratégias para lidar melhor com os alunos e com questões envolvendo conhecimentos pedagógicos gerais. Ambas apresentaram uma significativa carência referente ao domínio do conteúdo específico. Além disso, a aspirante focava suas análises em sua própria prática, e a experiente na aprendizagem de seus alunos. Em oposição ao esperado, ou seja, que a professora aspirante pudesse aprender mais sobre como ensinar com seu par experiente, houve aprendizagem de ambas as partes e uma ampliação em suas "bases de conhecimentos para o ensino".

Corte (2010), a partir da análise qualitativa de um estudo de caso de uma universidade pública, defende a tese de que o estágio curricular do curso de Pedagogia repercute na formação de qualidade do pedagogo e está relacionado às políticas educacionais, à organização curricular e à cultura organizacional do curso, assim como às concepções e práticas dos professores formadores e dos futuros professores. Entre as principais contribuições do estágio supervisionado identificadas pelos resultados do estudo estão: entrecruzamento teoria e prática; sólido repertório de saberes; protagonismo docente e discente; interdependência institucional; interlocução ensino, pesquisa e extensão; cultura organizacional do curso articulada aos tempos e estratégias formativas.

Em um estudo de caso que contemplou 12 cursos de licenciatura e 34 participantes, Wielewicki (2010) examinou a relação entre universidade e escola em atividades de prática de ensino. Os 
resultados indicam que o arranjo institucional dos dois universos pesquisados - a universidade e a escola - não favorece maior envolvimento dos docentes universitários das licenciaturas com o contexto da escola e tampouco ajuda a promover uma relação mais igualitária entre as instituiçõos e atores envolvidos. Além disso, tal organização reflete e produz isolamento no âmbito dessas instituições e atores e não contribui para evidenciar o potencial formativo que ambas podem ter. $\mathrm{O}$ estudo apresenta também, como contraponto, uma situação de parceria institucional entre uma grande universidade norte-americana e as escolas públicas em seu entorno, buscando discutir avanços e limitações em termos da relação entre ambas instituições nos contextos dos dois países.

Rosa (2010) realizou um estudo com professores em formação no curso de Pedagogia da Universidade Federal do Maranhão (UFMA) sobre extensão universitária na formação inicial de professores, tendo como foco a relação entre o desenvolvimento de atividades de extensão e os possíveis saberes produzidos no campo acadêmico. O trabalho tratou de um modelo específico, o Projeto Escola-Laboratório: uma alternativa para a melhoria do Ensino Fundamental, realizado no contexto do Estágio Supervisionado em Docência do Ensino Fundamental. Para ela, a extensão universitária produz saberes diferenciados e necessários aos futuros professores e a experiência proposta pelo projeto em questão articula, na formação dos professores emergentes do estágio supervisionado, ensino, pesquisa e extensão de forma indissociável.

Essas quatro teses que compõem o Bloco 1, defendidas em 2006 e 2010, abordam, sob perspectivas diferentes, a formação inicial docente, tendo em comum a preocupação com as análises sobre limites e potencialidades da relação escola-universidade para a formação do futuro professor e para o desenvolvimento profissional docente, com vistas à melhoria da educação básica. Elas evidenciam e corroboram achados já sinalizados pelo referencial teórico adotado neste artigo.

Tais evidências corroboram as afirmações de Panizzolo et al. (2012) quando abordam questões sobre o potencial dos estágios supervisionados e da parceria escola-universidade na formação inicial docente.

Assim como nas pesquisas do Bloco 1, as três teses agrupadas no Bloco 2, defendidas em 2004, 2011 e 2012, têm como foco a formação inicial de professores. O diferencial aqui é que os estudos analisam tal formação sob a perspectiva da trajetória profissional e do uso de narrativas escritas. Na primeira delas, Souza (2004) analisa as implicações e a fertilidade das narrativas de formação e suas relações com o estágio supervisionado, tomando como base narrativas desenvolvidas por dez alunas de um curso de licenciatura em Pedagogia num projeto de formação inicial de professores. A tese conclui 
que a fecundidade da epistemologia da formação e do estágio como iniciação revela, a partir da abordagem experiencial, elementos e rituais pedagógicos concebidos nas identidades e subjetividades das histórias de vida no processo de formação inicial, ao permitir às futuras professoras, através de suas experiências formadoras e recordações-referências da trajetória de escolarização, estabelecer novos sentidos ao trabalho escolar e à sua própria prática.

A pesquisa de Silva (2011) teve como objeto de análise um programa específico. Aqui, a autora socializa a pesquisa realizada durante o processo de formação inicial de professores com estudantes do $3^{\circ}$ ano do curso de Licenciatura em Pedagogia, sobre o caso de três participantes do Projeto Integrado desenvolvido na Unicamp. A tese teve como objetivo investigar e compreender como o estágio influenciou a relação das estudantes com a docência. A partir da análise das narrativas produzidas pelas participantes, a autora conclui que o referido modelo de estágio contribuiu para a reatualização de discursos que as estudantes já faziam (ouviam), mas, ao mesmo tempo, foi capaz de operar com a entrada de novos sentidos na relação com a docência.

Bizarro (2012) encerra o Bloco 2 da Tabela 3, com seu estudo sobre as possíveis contribuições do Projeto Pedagógico do Curso na formação do pedagogo da Universidade de Pernambuco, Campus Garanhuns, no período de 1996 a 2010, tendo em vista a concepção e a realização dos estágios supervisionados. Portanto, o estudo de Bizarro (2012) também analisa um projeto específico de estágio, na medida em que considera um único curso de Licenciatura em Pedagogia. Optou por uma investigação de predominância teórica, complementada com uma pesquisa de campo que contou com a aplicação de um questionário composto por seis questões discursivas, tendo 38 pedagogos egressos como sujeitos de pesquisa. O estudo defende a tese de que a formação do pedagogo na Universidade de Pernambuco/Campus Garanhuns deva considerar as possíveis contribuições que o Projeto Pedagógico de Curso poderá oferecer ao contemplar, em suas diversas áreas de atuação, os estágios supervisionados como momentos/espaços formativos e que podem influenciar a construção das identidades e o desempenho profissional dos egressos.

As três teses do Bloco 2 aproximam-se pelo interesse nas experiências de estágio como contexto de pesquisa. O que as difere das pesquisas do Bloco 1 é que suas analises focam, de modo específico, a potencialidade do uso de narrativas como ferramenta de sistematização e reflexão na e sobre a prática.

E é justamente a reflexão na e sobre a prática o foco das pesquisas que caracterizam o Bloco 3 das teses ora analisadas. Desse modo, pode-se intuir que a formação inicial de professores, mediada por experiências práticas supervisionadas em estágios e/ou projetos de extensão sistematizadas e analisadas na perspectiva da prática reflexiva, permeia o universo das teses presentes nos Blocos 2 e 3. 
De modo específico, os estudos que compõem o Bloco 3 consideram a formação do professor na perspectiva do professor-pesquisador/reflexivo. No primeiro deles, Ventorim (2005) investigou a produção científica apresentada sobre a formação do professor-pesquisador em quatro edições do ENDIPE (Encontro Nacionais de Didática e Prática de Ensino), realizadas no período de 1994 a 2000. Ao final da análise de 77 trabalhos, o estudo concluiu que o campo científico da área de didática e prática de ensino reconhece a temática formação do professor-pesquisador em suas produções. Além disso, apontou o desenvolvimento da pesquisa na formação e na ação docente como fértil para uma formação e uma prática de qualidade, favorecendo o desenvolvimento profissional. Por fim, indicou a necessidade de outra relação com o conhecimento e seu processo de construção, buscando questionar certezas e fomentar novas lógicas, tendo como eixo norteador uma concepção do conhecimento como processo.

A segunda tese desse Bloco 3, de autoria de Signorini (2006), tem como objeto de investigação estratégias de ensino a partir de experiências desenvolvidas durante a disciplina de Pesquisa Educacional na Prática Pedagógica I e II, com turmas ingressantes de um curso de Licenciatura em Pedagogia. Enfatizou a pesquisa como base da formação inicial e, como Ventorim (2005), fez uma análise sob a perspectiva do professor-pesquisador. Para Signorini (2006), os dados apresentam contribuições contundentes e indicam que a pesquisa é um encaminhamento metodológico com bom potencial para a formação do professor como profissional crítico, criativo, investigador de sua própria prática e produtor de conhecimentos de modo colaborativo.

Seja tomada a partir da produção de narrativas (teses do Bloco 2) ou como instrumento formativo (teses do Bloco 3), as contribuições da reflexão para a formação docente são amplamente difundidas por estudiosos da área de formação de professores e muitos são seus representantes (DEWEY, 1933; SCHÖN, 1983; STENHOUSE, 1983; CONTRERAS, 2002; ROGERS, 2002; ZEICHNER, 2008). Apesar de a prática reflexiva ser, como sugerem os pesquisadores Ventorim (2005) e Signorini (2006), um dos caminhos para que os professores compreendam o papel que assumem enquanto parte de uma organização maior, configurada sob a perspectiva de intervenções realizadas por suas próprias contribuições (CONTRERAS, 2002), é necessário cuidado para que essa linha não seja cegamente abraçada, como um slogan perverso, que culpabiliza a vítima, colocando unicamente no professor o peso de suas ações pedagógicas. Neste sentido, Zeichner (2008) apresenta análises contundentes, que merecem ser consideradas:

Apesar de todos esses e outros desenvolvimentos nos trabalhos sobre a reflexão docente, existe ainda, na minha visão, muita confusão conceitual sobre o que as 
pessoas realmente querem dizer quando usam o termo "reflexão" - se estão procurando desenvolver uma forma real de aprendizagem docente que vai além de uma implantação obediente de orientações externas, e mesmo se essa aprendizagem docente auxiliou para que fosse real, e se existe uma ligação de seus esforços com lutas dentro e fora da educação para tornar o mundo um lugar mais justo socialmente para todos. (ZEICHNER, 2008, p. 247).

Os Blocos 4 e 5 tratam, respectivamente, da formação inicial de professores online e da qualidade da formação em curso de Pedagogia na perspectiva de egressos. Na tese do Bloco 4, Vieira (2009) analisa como objeto de investigação o valor ético-político e pedagógico do conhecimento dos professores das Séries Iniciais do Ensino Fundamental que participaram do Projeto Veredas Formação Superior de Professores 2002-2005, identificando as possibilidades, os limites e os desafios desta formação. A análise centra-se nas mensagens do fórum de discussão do Projeto Veredas da Agência de Formação UFJF. Para a autora, os dados evidenciam que, em razão da influência de órgãos internacionais, sobretudo do Banco Mundial, nas políticas educacionais e nos cursos de formação inicial de professores, em especial naqueles realizados com a utilização das TIC (Tecnologias da Informação e Comunicação) $)^{8}$, ministrados por instituições superiores públicas, entre 2000 e 2005 , foram disseminados conteúdos e valores ligados ao senso comum, direcionados para a apropriação do domínio de técnicas e métodos de ensino que ressaltam o treinamento do professor para a aquisição de conhecimentos, mantendo a hegemonia capitalista em sua fase neoliberal. Assim como fizeram Vieira (2009), Rosa (2010), Silva (2011) e Bizarro (2012), debruça-se sobre a investigação de um programa de formação bem específico, o que sugere ser uma tendência nas pesquisas da área, ao menos na amostra por nós considerada.

Vale ressaltar, ainda em relação a Vieira (2009), que as tecnologias digitais de informação e comunicação (TDIC) (BELLONI, 2009; KENSKI, 2011; SANCHO, 2013) ganharam espaço no cenário acadêmico mais recentemente. Apesar de não se mostrar representativa no recorte feito por nós (talvez pela época em que o Veredas foi desenvolvido), a formação de professores por meio de TDIC tem se mostrado uma temática recorrente em pesquisas da área. Isso decorre, dentre outros aspectos, das potencialidades das TDIC, sobretudo em função da flexibilidade pedagógica que oferecem, já evidenciadas pela literatura (LEVY, 1999; SANCHO, 2013; TUBELLA et al., 2013; MILL, 2014).

$\mathrm{Na}$ última tese analisada (Bloco 5), Vieira (2010) investigou, sob a perspectiva de egressos de um curso de Pedagogia, a qualidade da formação que lhes foi oferecida. Foram analisados os principais indicadores de qualidade formulados e apontados para o processo de formação inicial de pedagogos. Além de uma revisão bibliográfica, o autor classifica a pesquisa como estudo de caso. Os participantes desta pesquisa foram estudantes, entre os anos 2000 e 2009, do curso de Licenciatura em Pedagogia da 
Unochapecó. A investigação sugere que a especificidade e a multidimensionalidade da atuação profissional do pedagogo exigem uma formação inicial que leve em consideração a reflexão sobre: a) parâmetros de qualidade utilizados em mudanças ocorridas no processo de formação do pedagogo ao longo da história da educação superior e do curso de Pedagogia; b) movimentos e preocupações com a qualidade da formação inicial de pedagogos nas políticas da educação superior; c) impactos gerados com o desenvolvimento da qualidade no processo de formação inicial de pedagogos; e d) referências, ações e condições essenciais necessárias à melhoria do processo de formação inicial de pedagogos.

A leitura dos resumos desses 11 trabalhos indicou que os estudos vão ao encontro do referencial teórico a que recorremos. Os autores evidenciaram preocupação com uma formação inicial de qualidade, no sentido de oferecer aos futuros professores momentos de "simulação" da prática docente, de modo orientado e supervisionado. Tais análises são importantes para a compreensão da questão pela área, mas, ao mesmo tempo, centram-se em programas já existentes. Isto é, são análises contundentes e de grande contribuição para a área, mas pecam por não dar atenção ou fomentar a constituição de terrenos em que novas possibilidades formativas pudessem emergir.

Confrontando as descobertas deste estudo bibliométrico com investigações feitas por autores interessados na mesma temática, identificamos que levantamentos feitos por Gatti (2003) e Lüdke (2012), por exemplo, concluem que as pesquisas sobre a formação dos professores focalizam, cada vez mais, temas centrados no dia a dia do trabalho docente. Para elas, se por um lado a pesquisa sobre o cotidiano do trabalho docente, imbuída das características da pesquisa-ação, contribui para que o conceito de professor-pesquisador se fortaleça; por outro, incorre no risco de deslizes metodológicos, análises superficiais, grande preocupação com a "aplicabilidade" da pesquisa em outros contextos, sucessividade de modismos e conclusões bastante imediatas, o que justifica a nossa preocupação com o tema.

O que se vê aqui, no entanto, não se trata de uma preocupação com a aplicabilidade dos estudos em pauta. Os autores das teses aqui discutidas, em geral, empreenderam seus esforços em análises de programas sob a perspectiva de uma contribuição para a formação do futuro professor.

\section{Considerações finais}

O estudo aqui desenvolvido teve como objetivo mapear as produções científicas (teses) defendidas entre os anos 2000 e 2012, em programas de pós-graduação em Educação, disponíveis na 
rede mundial de computadores que tratavam da aprendizagem da docência por meio de processos formativos em contexto escolar. Foram elencadas 11 pesquisas que, ao tratarem da formação de inicial de professores, o faziam sob pelo menos uma das perspectivas listadas a seguir: 1. contribuições de inserções em contexto escolar; 2. relações de parceria escola-universidade; 3. papel da reflexão nesta formação e 4. identificação de programas formativos, como projetos de extensão universitária, visando à aproximação ao contexto de trabalho futuro.

As perspectivas delineadas acima foram construídas em consonância com o referencial teórico abordado por nós, para quem a interlocução entre cada uma delas sugere uma formação inicial que busca atender às necessidades emergentes na fase inicial da carreira docente e minimizar aspectos negativos inerentes aos primeiros contatos com a profissão.

Em síntese, as teses analisadas contemplaram aspectos importantes da aprendizagem da docência, como, por exemplo: as potencialidades formativas de atividades de inserção em contexto escolar e de parcerias escola-universidade para a formação inicial do professor; a formação inicial de professores sob a ótica da trajetória profissional e do uso de narrativas escritas; a formação docente mediada por processos reflexivos; a formação inicial de professores online e, por fim, a investigação sobre qualidade da formação em curso de Licenciatura em Pedagogia na perspectiva de egressos, tendo em vista o perfil profissional do pedagogo.

Por outro lado, análises apresentadas sugerem que, apesar de haver publicações relevantes para a área, a formação em contexto, caracterizada por experiências que vão além das Práticas de Ensino e dos Estágios Supervisionados, a temática não está inserida no cenário acadêmico de modo representativo. Tal constatação não tem o intuito de desqualificar as temáticas priorizadas pelas teses defendidas entre os anos 2000 e 2012, e sim sugerir possibilidades para a realização de novas pesquisas.

Averiguou-se ainda que as pesquisas versam sobre programas formativos institucionais e que em nenhuma delas foi possível identificar a criação de um espaço formativo, caracterizado também enquanto intervenção da pesquisa. A análise de programas institucionais já existentes é de grande importância e um dos possíveis indicadores da qualidade dos cursos de formação inicial oferecidos em instituições públicas. No entanto, nosso estudo indica a carência de construção, implementação e análise de novos programas. De espaços formativos concebidos sob a perspectiva híbrida ou virtual, por exemplo, tão em voga na atualidade. 
Fica o convite aos pesquisadores interessados na formação inicial de professores. Afinal, ao considerarmos que se trata do primeiro momento formal de aprendizagem da docência ${ }^{9}$, ela demanda pesquisa e maior visibilidade no interior de programas de pós-graduação em educação.

\section{Notas}

${ }^{1}$ Saiba mais em: www.portaldosprofessores.ufscar.br.

${ }^{2}$ Na catalogação da Base de Teses, foram consideradas as produções disponíveis virtualmente nas páginas de internet das próprias instituições ou da Capes. A catalogação foi concluída em meados de 2013.

${ }^{3}$ Access é uma ferramenta de banco de dados relacional da Microsoft®.

${ }^{4}$ Ver notas/classificação da Capes em: <http://conteudoweb.capes.gov.br/conteudoweb/ProjetoRela caoCursosServlet?acao $=$ pesquisarIes $\&$ codigoArea $=70800006 \&$ descricaoArea $=\&$ descricaoAreaConhecim ento=EDUCA\%C7\%C3O\&descricaoAreaAvaliacao=EDUCA\%C7\%C3O >. Acesso em: 27 fev. 2014.

${ }^{5}$ Considerando que uma tese é concebida 3 ou 4 anos antes da defesa, podemos trabalhar com um recorte de 10 a 15 anos de interesse na temática.

${ }^{6}$ A quantidade líquida de teses é apurada pela eliminação de teses duplicadas; isto é, se a tese possui dois ou mais dos termos, ela é computada apenas uma vez. Por exemplo, quando uma tese trás os termos "estágio" e "aprendizagem docente" no título ou nos termos chave, ela foi contabilizada duas vezes, mas ao final ela só foi computada uma vez entre as 83 teses. Ou seja, as 83 teses não se repetem.

${ }^{7}$ Universidade Estadual do Rio de Janeiro (UERJ); Universidade Federal da Bahia (UFBA); Universidade Federal de Minas Gerais (UFMG); Universidade Federal do Rio Grande do Sul (UFRGS); Universidade Federal de São Carlos (UFSCar); Universidade de Brasília (UnB) e Universidade Estadual Paulista, campus Marília (Unesp).

${ }^{8}$ Registra-se aqui que fizemos parte do Projeto Veredas (em outra instituição), mas não adotávamos tecnologias digitais no processo de ensino-aprendizagem. As TIC adotadas não eram digitais e era facultado à instituição o uso de tecnologias de comunicação simples como e-mail ou site. Nunca foram usados ambiente virtual de aprendizagem, webconferência ou fóruns virtuais ou outras tecnologias digitais.

\section{REFERÊNCIAS}

ANDRE, M. Questões sobre os fins e os métodos de pesquisa em educação. In: Revista eletrônica de Educação. São Carlos, SP: UFSCar, v.1, $\mathrm{n}^{\circ}$ 1, p. 119-131, set. 2007. Disponível em: <www.reveduc.ufscar.br>. Acesso em 12 dez. 2014.

ANDRE, M. ANDRE, Marli. Políticas e programas de apoio aos professores iniciantes no Brasil. Cad. Pesqui., São Paulo, v. 42, n. 145, p. 112-129, Abr. 2012. Disponível em: $<$ http://www.scielo.br/scielo.php?script=sci_arttext\&pid=S010015742012000100008\&lng=en\&nrm=iso>. Acesso em: 12 dez. 2014.

ARAUJO, R. F.; ALVARENGA, L. A bibliometria na pesquisa científica da pós-graduação brasileira de 1987 a 2007. Enc. Bibli.: R. Eletr. Bibliotecn. Ci. Inf., v. 16, n. 31, p. 51-70, 2011. Disponível em: <https://periodicos.ufsc.br/index.php/eb/article/view/1518-2924.2011v1 6n31p51/17757>. Acesso: 15 dez. 2014. 
BIZARRO, A. M. Formação do pedagogo: um olhar sobre a trajetória profissional dos/as egressos/as do curso de licenciatura em Pedagogia da UPE-Campus Garanhuns de 1996 a 2010. 2012. 199f. Tese (Doutorado em educação) - Universidade Estadual do Rio de Janeiro, Rio de Janeiro, 2012.

BRASIL. Lei de Diretrizes e Bases da Educação Nacional. Lei nº. 9394/1996, de 20 de dezembro de 1996. Diário Oficial [da] República Federativa do Brasil, Poder Executivo, Brasília, DF, 23 dez. 1996, p. 27833.

BRASIL, Diretrizes Nacionais para a Licenciatura em Pedagogia, em 2005.

BELlONI, M. L. O que é mídia-educação. 3. ed. Campinas, SP: Autores Associados, 2009. (Coleção polêmicas do nosso tempo).

CAVACO, M. H. Ofício do professor: o tempo e as mudanças. In: NÓVOA, A. (org.) Profissão professor. 2. ed. Porto: Porto Editora, Portugal, 1995. p. 162-191.

COCHRAN-SMITH, M. Aprender a ensinar na profissão docente. In: CONGRESSO INTERNACIONAL SOBRE PROFESSORADO PRINCIPIANTE E INSERÇÃO PROFISSIONAL À DOCÊNCIA, 4, Curitiba, 2014. (Conferência de abertura).

CONTRERAS, J. A autonomia de professores. São Paulo: Cortez, 2002.

CORTE, M. G. O estágio curricular e a formação de qualidade do pedagogo. 2010. 315f. Tese (Doutorado em Educação) - Pontifícia Universidade Católica, Porto Alegre, 2010.

DAL-FORNO, J. P., CARDOSO, L. C. e RINALDI, R.P. Da construção de ma proposta de estágio na modalidade a distância: a experiência da UFSCar. In: Olhares. Guarulhos: SP. Vol.1, n. 1. p. 349-377, maio, 2013.

DEWEY, J. How we think: a restatement of the relations of refletive thinking to the educative process. $2^{a}$ edição. Boston: DC Heath, 1933.

FEIMAN-NEMSER, S.; BUCHMAN, M. Lagunas de lãs prácticas de eneñanza de los programas de formación Del profesorado. In: VILLAR ÂNGULO, L. M. (Ed.). Conocimento, creencias y teorias de los profesores. Alicante: Marfil, 1988. P.301-508.

FLORES, M. A. Algumas reflexões em torno da formação inicial de professores. In: Educação, Porto Alegre, v. 33, n 3, p. 182-188, set./dez. 2010.

GARCIA, C. M. Formação de Professores para uma mudança educativa. Porto: Porto Editora, 1999.

, Los profesores como trabajadores del conocimiento. Certidumbres y desafíos para una formación a lo largo de la vida. In: Educar, v. 30, 2002. p. 27-56.

GATTI B. A. Formação de professores, pesquisa e problemas metodológicos. In: Contrapontos. Itajaí V. 3. p. 381-392, set./dez. 2003. 
, GATTI, B. A. O início da carreira docente no Brasil: formas de entrada, primeiras experiências profissionais e políticas educacionais. In: CONGRESSO SOBRE PROFESORADO PRINCIPIANTE E INSERCIÓN PROFESIONAL A LA DOCÊNCIA, 3. Santiago do Chile, 2012. Anais... Disponível em: <http://prometeo.us.es/congreso/mesas/gatti.pdf>. Acesso em: 23 jun. 2012.

; BARRETO, E. S. S.; ANDRE, M. Políticas docentes no Brasil - um estado de arte. Brasília: UNESCO, 2011.

KAGAN, D. Professional Growth Among Preservice and Begning Teachers. Review of Educational Research, v. 62, n², p. 129-170, 1992.

KENSKY, V. M. Tecnologias e ensino presencial e a distância. Campinas, SP: Papirus, 2003. - (Série Prática Pedagógica)

, Educação e tecnologias: o novo ritmo da informação. 8. ed. Campinas, SP: Papirus, 2011. (Coleção Papirus Educação).

LEVY, P. Cibercultura. São Paulo: Ed.34, 1999.

LONGHINI, M. D. Ensinando a ensinar ou vivendo para aprender? A interação entre os conhecimentos de um professor atuante e de um aspirante, como subsídio para aprendizagem da docência. 2006. 293f. Tese (Doutorado em Educação) - Universidade Federal de São Carlos, São Carlos, 2006.

LORTIE, D. The Schoolteacher: A sociological study. Chicago: University of Chicago Press, 1975.

LÜDKE, M. Desafios para a pesquisa em formação de professores. In: Rev. Diálogo Educ. Curitiba. v. 12, n 37, p. 629-646, set./dez. 2012.

MARCELO, C.; VAILLANT, D. Ensinando a ensinar - as quatro etapas de uma aprendizagem. Curitiba. UTFPR, 2012.

MARIANO, A. L. S. A construção do início da docência: um olhar a partir das produções da ANPEd e do ENDIPE. São Carlos: UFSCar, 2006, 142p. (Dissertação de Mestrado).

; LIMA, E. F. de. A pesquisa sobre o início da docência a partir da ENPEd e do ENDIPE. In: REALI, A. M. de M. R.; MIZUKAMI, M. da G. (orgs.). Desenvolvimento profissional da docência: teorias e práticas. São Carlos: EdUFSCar, 2012.

MATTOS, L. C. "Bibliometria": a metodologia acadêmica convencional em questão. RAE-eletrônica, v.3, n.2, 2004. Disponível em: <www.scielo.br/pdf/raeel/v3n2/v3n2a16>. Acesso: 15 dez. 2014.

MILL, D. Flexibilidade educacional na cibercultura: analisando espaços, tempos e currículo em produções científicas da área educacional. In: RIED. Revista Iberoamericana de Educación a Distância, v. 17, n², p. 97-126, 2014. 
MIZUKAMI, M. G. N. Aprendizagem da docência: algumas contribuições de L. S. Shulman. In: Revista do Centro de Educação. Edição 2004, vol. 29, nº 02, Santa Maria, RS.

; REALI. A. M. R. de M. O professor a ser formado pela UFSCar: uma proposta para a construção de seu perfil profissional. In: PIERSON, A. H. C.; OLIVEIRA, M. H. A. de. Formação de professores na UFSCar - concepção, implantação e gestão de projetos pedagógicos das licenciaturas. São Carlos: EdUFSCar, 2010. 17-36.

MORETTI, V. D. A articulação entre a formação inicial e continuada de professores que ensinam matemática: o caso da Residência Pedagógica da Unifesp. In: Educação, Porto Alegre, v. 34, n 3, p. 385-390, set./dez. 2011.

PANIZZOLO, C. et al. Programa de residência pedagógica da UNIFESP: avanços e desafios para a implantação de propostas inovadoras de estágio. In: ENDIPE - ENCONTRO NACIONAL DE DIDÁTICA E PRÁTICAS DE ENSINO, 16. UNICAMP, Campinas. Anais... Campinas: Junqueira \&Marin Editores. p. 221-233, 2012.

PENIN, S. T. de S. Pedagogia, formação de professores e as diretrizes curriculares nacionais para o curso de Pedagogia. In: PINHO, S. Z. de (Org.). Formação de educadores: dilemas contemporâneos. São Paulo: Editora Unesp, 2011, p.61-68.

REALI. A. M. R. de M.; TANCREDI, R. M. S. P. Portal dos Professores da UFSCar: um espaço virtual de desenvolvimento profissional da docência. In: PIERSON, A. H. C. e OLIVEIRA, M. H. A. de. Formação de professores na UFSCar - concepção, implantação e gestão de projetos pedagógicos das licenciaturas. São Carlos: EdUFSCar, 2010, p. 255-281.

ROGERS, C. Defining Reflection: Another Look at John Dewwy anda Reflective Thinkng. In: Teachers College Record. v. 104, n 4, jun. 2002, p. 842-866.

ROMERO, I. B. Mentores y Noveles: historias del trayecto. Organización de Estados Iberoamericanos para la Educación, Ciencia y Cultura - IDIE Chile Formación Docente. Chile, 2011.

ROSA, M. M. Tecendo uma manhã: o estágio supervisionado no curso de Pedagogia mediado pela extensão universitária. 2010, 155p. Tese (Doutorado em Educação) - Universidade do Estado de São Paulo, Marília, 2010.

SANCHO, J. M. G. La educatión superior a distancia em La sociedad digital: retos y oportunidades. In: FIDALGO, F. S. R. et al. (org.) Educação a distância - meios, atores e processos. CAED-UFMG, Belo Horizonte, MG. 2013, p.19-38.

SANTOS, R. N.; KOBASHI, N. Y. Bibliometria, cientometria, infometria: conceitos e aplicações. Pesquisa Brasileira em Ciência da Informação, v.2, n.1, p.155-172, 2009. Disponível em: <http://inseer.ibict.br/ancib/index.php/tpbci/article/view/21/43>. Acesso: 15 dez. 2014.

SCHOENFELD, A. H. Toward a theory of teaching-in-context. In: Issuis in Education. v. 4. N. 1, p. 194, 1998. Disponível em: <http://vocserve.berkeley.edu/faculty/ahscho enfeld/Schoenfeld_TeachingInContext.pdf>. Acesso: 12 dez. 2014. 
SCHÖN, D. A. The reflective practioner. How professionals think in action. Londres, Temple Smith. 1983.

SIGNORINI, N. T. A pesquisa na formação de professores: a perspectiva do professor pesquisador. 2006. 180f. Tese (Doutorado em Educação) - Universidade de Campinas, Campinas, 2006.

SOUZA, E. C. O conhecimento de si: narrativas do itinerário escolar e formação de professores.2004. 442f. Tese (Doutorado em educação) - Universidade Federal da Bahia, Terra, UFBA, 2004.

SHULMAN, L. S. Knowledge and teaching: foundations os the new reform. In: Harvard Educational Review, 57, 1. p. 1-22. 1987.

, Conocimento y enseñanza: fundamentos de la nueva reforma. In: Profesorado. Revista de currículum y formación del professorado, 9, 2, 2005.

SILVA, K. C. Formação inicial de professores: problematizações, reatualizações de discursos e produção de narrativas. 2011. 136f. Teses (Doutorado em Educação) Universidade Estadual de Campinas, Unicamp, 2011.

STENHOUSE, L. The relevance of practice to theory. Theory into Practice, v. 22, n. 3, p. 211-215. 1983.

TUBELLA, I.; GROS, B.; MAS, X.; MACAU, C. Flexible education. eLearning Papers, n.24, p. 1-11, 2011. Disponível em: <http://elearningpapers.eu/sites/default/fi les/media25537.pdf>. Acesso: 15 jul. 2013. Acesso: 9 jul. 2013.

VENTORIM, S. A formação do professor pesquisador na produção científica dos encontros nacionais de didática e prática de ensino: 1994-2000. 2005. 346f. Tese (Doutorado em Educação) Universidade Federal de Minas Gerais, Belo Horizonte, 2005.

VIEIRA, F. M. A formação inicial de professores on-line: possibilidades, contradições e desafios: 2000-2005. 2009. 385f. Teses (Doutorado em Educação) - Universidade de Brasília, Brasília, UnB, 2009.

VIEIRA, J. A. Qualidade da formação inicial de pedagogos: indicadores na visão de egressos. 2010. 211f. Tese (Doutorado em Educação) - Pontifícia Universidade Católica, Porto Alegre, PUC, 2010.

WIELEWICKI, H. G. Prática de ensino e formação de professores: um estudo de caso sobre a relação universidade-escola em cursos de licenciatura. 2010. 244f. Tese (Doutorado em Educação) Universidade Federal do Rio Grande do Sul, Porto Alegre, 2010.

ZEICHNER, k.; GORE, J. Teacher socialization. In: R. Houston (Ed.), Handbook of Research on Teacher Education. New York: Macmillam, 1990. p. 329-348.

, Uma análise crítica sobre a "reflexão" como conceito estruturante na formação docente. In: Educ. Soc. Campinas, v. 29, $\mathrm{n}^{\circ}$ 103, p. 535-554, maio/ago. 2008. Disponível em: <www.cedes.unicamp.br>. Acesso em: 12 dez. 2014. 


\section{The teachers initial training and the insertion in scholastic context: a bibliometrics study}

\begin{abstract}
From the perspective that the teaching career is lifelong built and that the initial formation is shown as a singular moment in the process, this work seeks to reveal the representativeness of the initial formation thematic linked to teachers' teaching-in-context experiences in Brazilian research. Therefore, 3,468 theses from Education Post Graduation Programs cataloged in the basis of the Novo Horizonte Group (Study and Research Group on Innovation in Education, Technology and Languages from the Federal University of São Carlos - UFSCar) have been taken as object of study. The bibliometric research reveals that the initial formation, mediated by experiences in school settings, is present in 11 theses from a total of 3,468 works. The analyzes indicate that, although there are relevant studies to the field, the in-context formation (marked by experiences that go beyond the Teaching Practice and Supervised Internship), is not representatively inserted in the academic scenario. Among some important contributions to the line of teacher formation, the study also indicated that researches addressed institutional formation programs and that in none of them it was possible to identify the creation of a formation space, characterized also as research intervention, suggesting a possible lack of construction, implementation and analysis of new programs, such as formation spaces designed under the hybrid or virtual perspective.
\end{abstract}

Keywords: Teacher formation. Professional learning. Teaching practice.
La formación inicial de los profesores y la inclusión en el entorno escolar: un estudio bibliométrico

\section{Resumen}

A partir de una perspectiva de que la profesión docente se construye durante toda la vida y que la formación inicial constituye un momento singular en este proceso, este estudio tuvo por objetivo conocer la representatividad de la temática formación inicial del profesorado vinculado a las experiencias de enseñanza-encontexto en la investigación brasileña. Así, se realizó un estudio bibliométrico de 3.468 tesis doctorales en Educación catalogadas en la base de datos del Grupo Horizonte (Grupo de Estudios e Investigación sobre Innovación en Educación, Tecnologías y Lenguajes UFSCar). La investigación bibliométrico reveló que la formación inicial, desarrollada por las experiencias en el entorno escolar, está presente en 11 de las 3.468 tesis analizadas. Los análisis indican que hay algunos estudios relevantes sobre el tema. Sin embargo, esta área de estudio aún no se incorpora al contexto académico de manera representativa. Por otra parte, la mayoría de las investigaciones sólo analiza la práctica docente y de prácticas supervisadas. Entre algunas contribuciones importantes a la línea de la formación docente, el estudio también indicó que las obras se ocupan de los programas de capacitación institucional y que ninguno de ellos analiza ni propone la creación de un espacio de formación, también caracterizada como una intervención práctica de la investigación. Esto sugiere una posible falta de construcción, implementación y análisis de nuevos programas, como espacios formativos diseñados a partir de la perspectiva híbrida o virtual.

Palabras clave: Formación del profesorado. Aprendizaje profesional. La práctica docente. 


\section{Luciana Cristina Cardoso}

E-mail: lucianacardoso.uab@gmail.com

Daniel Mill

E-mail: mil.ufscar@gmail.com
Enviado em: 11/12/2015

Aprovado em: 05/06/2016

\section{Maria Iolanda Monteiro}

E-mail: iolanda.uab@gmail.com 